\title{
PENYULUHAN BAHAYA NARKOBA TERHADAP ANAK - ANAK SD
}

\author{
Haerudin $^{1}$ Tia Latifatu Sa'diyyah ${ }^{2}$ Tarpan Suparman $^{3}$ \\ Universitas Buana Perjuangan Karawang \\ ${ }^{1}$ haerudin@ubpkarawang.ac.id \\ 2tia.latifatu@ubpkarawang.ac.id \\ 3.tarpan.suparman@ubpkarawang.ac.id
}

\begin{abstract}
Abstrac
Community Service is the goal to provide insight, knowledge and understanding of the types and dangers that can be caused during drug completion. The method used in this study is a method, question and answer, and developed through media images and videos. The results of this activity can be used by students from 10 to 90 about drugs, this can be seen when students ask students of SDN Wanajaya II, which students are expected to avoid drugs. Community Service Activities intersect with students who are Class 5 in SDN Wanajaya II running smoothly, students also pay close attention and look enthusiastic from beginning to end.
\end{abstract}

Keywords : Narcotics Hazards, Types and their use

\begin{abstract}
Abstrak
Pengabdian Kepada Masyarakat ini bertujuan untuk memberikan gambaran, pengetahuan dan pemahaman tentang jenis dan bahaya yang dapat ditimbulkan pada penyalahgunaan narkoba. Metode yang digunakan dalam kegiatan ini metode ceramah, tanya jawab, dan simulasi jenis jenis narkoba dan bahaya narkoba melalui media gambar dan vidio. Hasil dari kegiatan ini adalah dapat meningkatnya pemahaman siswa siswi dari 10 menjadi 90 tentang narkoba, hal ini terlihat ketika diberikannya kesempatan untuk bertanya kepada siswa siswi SDN Wanajaya II, yang nantinya siswa siswi diharapakan bisa terhindar dari narkoba. Kegiatan Pengabdian Pada Masyarakat ini penyuluhan pada sisw asiswi Kelas 5 SDN Wanajaya II berjalan lancar, sisiwa siswi juga memperhatikan dengan baik dan terlihat antusias dari awal sampai akhir.
\end{abstract}

Kata Kunci : Bahaya Narkoba, Anak SD 


\section{PENDAHULUAN}

Masalah narkoba saat ini telah merasuki semua elemen bangsa, mulai dari anakanak hingga orang dewasa, dari kalangan bawah sampai pejabat, bahkan kalangan politisi dan penegak hukum juga tidak steril dari penyalahgunaan narkoba, sehingga upaya pemberantasannya tidak cukup hanya ditangani oleh pemerintah dan aparat penegak hukum saja melainkan perlu melibatkan seluruh masyarakat untuk berperan dan berpartisipasi aktif dalam pencegahan dan pemberantasan terhadap penyalahgunaan dan peredaran narkoba. Indonesia termasuk sebagai salah satu negara yang ditengarai sebagai tempat lintas narkoba, sehingga kejahatan narkoba bukan lagi kejahatan yang sifatnya lokal akan tetapi telah merebak sampai ke seluruh wilayah Indonesia dan sering dijadikan sebagai daerah transit oleh para pelaku sebelum sampai ke tempat tujuan (negara lain). Oleh sebab itu angka perkembangan kasus narkoba dari tahun ke tahun semakin meningkat. Terutama dikalangan pelajar penyalahgunaan narkoba telah menyusup didalam lingkungan pendidikan, mulai dari kampus, SMU, sampai kepada murid-murid sekolah dasar. Penyalah gunaan narkoba dapat merusak perkembangan jiwa generasi muda baik bagi si pengguna maupun orang lain. Narkoba sebagai zat yang sangat diperlukan untuk pengobatan dalam pelayanan kesehatan seringkali disalahgunakan tidak sesuai dengan standar pengobatan dan jika disertai peredaran narkoba secara gelap akan menimbulkan akibat yang sangat merugikan perorangan ataupun masyarakat, khususnya generasi muda bahkan dapat menimbulkan bahaya yang sangat besar bagi kehidupan dan nilai-nilai budaya bangsa yang pada akhirnya akan melemahkan ketahanan nasional. Narkoba dengan mudahnya dapat diperoleh bahkan sudah dapat diracik sendiri yang sulit dideteksi (Mardani, 2008).

Di Indonesia, data dari BNN RI menunjukan pada tahun 2004 bahwa 15\% dari jumlah penduduk Indonesia terlibat penyalahgunaan narkoba (3,2 juta jiwa) dan pada tahun 2005 menunjukan bahwa 15.000 orang meninggal setiap tahun akibat narkoba (Badan Narkotika Provinsi DKI Jakarta, 2009). Berdasarkan penelitian Prisaria (2012), semakin tinggi tingkat pendidikan, semakin banyak pelajar/mahasiswa 
penyalahgunaan yang menggunakan uang saku untuk membeli narkoba. Sebagian besar pelajar atau mahasiswa mulai menyalahgunakan narkoba pertama kali dengan alasan ingin coba-coba, untuk bersenang-senang, bujukan teman, masalah keluarga, dan masalah di sekolah (Survei Nasional BNN, 2011). Pada umumnya, narkoba disalahgunakan oleh mereka yang kurang mengerti efek samping yang ditimbulkan (Prisaria, 2012)

\section{Faktor-faktor Penyebab Penyalahgunaan Narkoba}

Pada Undang-Undang RI Nomor 35 Tahun 2009 Tentang Narkotika Bab II Pasal 4 Ayat (a), menyatakan bahwa: "menjamin kesediaan narkotika untuk kepentingan pelayan kesehatan dan/atau pengembangan ilmu pengetahuan dan teknologi". Sedangkan pada Bab III Pasal 7, menyatakan bahwa: "narkotika hanya dapat digunakan untuk kepentingan pelayanan kesehatan dan/atau pengembangan ilmu pengetahuan dan teknologi”. Namun, pada kenyataannya saat ini dalam lingkungan masyarakat yang terjadi adalah penyalahgunaan terhadap narkotika itu sendiri. Adapun beberapa faktor yang menjadi penyebab penyalahgunaan Narkotika pada seseorangterdiri dari :

\section{Faktor Individu}

Tiap individu memiliki perbedaan tingkat resiko untuk menyalahgunakan Narkoba. Faktor yang memengaruhi individu terdiri dari faktor keperibadian dan faktor konstitusi (Dedi humas,. 2016)

\section{Coba-coba}

Merasa tertarik dengan efek yang ditimbulkan oleh suatu zat yang dilarang, seseorang dapat memiliki rasa ingin tahu yang kuat untuk mencoba zat terlarang tersebut. Tanpa disadari oleh pengguna yang awalnya coba-coba itu dia akan menjadi ketagihan dan akan melakukannya lagi berulang-ulang tanpa bisa berhenti.

\section{Ikut-ikutan}

Orang yang sudah menjadi korban mungkin akan berusaha mengajak orang lain yang belum terkontaminasi narkoba agar ikut merasakan penderitaan yang dirasakannya. Pengedar dan pemakai biasanya pertama akan memberikan secara gratis barang haram 
itu. Seeorang yang melihat orang lain lagi asyik memakai zat terlarang bisa jadi akan mencoba mengikuti gaya pemakai tersebut termasuk menyalahgunakan tempat umum untuk menikmati zat terlarang tersebut.

\section{Untuk Melupakan Masalah}

Orang yang dirundung banyak masalah dan ingin lari dari masalah dapat terjerumus dalam penyalahgunaan narkoba, mereka berniat lari dari masalah meskipun cuma sesaat. Zat terlarang dapat membantu seseorang untuk melupakan masalah dan mengejar kenikmatan dengan jalan menggunakan narkoba yang menyebabkan halusinasi atau khayalan yang menyenangkan.

\section{Gaya Hidup}

Zat terlarang jenis tertentu dapat membuat pemakainya lebih berani, keren, percaya diri, kreatif, santai dan sebagainya. Jelas bagi orang yang ingin disebut gaul oleh golongan atau kelompok dia harus memakai zat tersebut (Dimas Djaka, 2008).

Adapun faktor pendorong penyalahgunaan narkoba dikalangan remaja dari data yang diperoleh menurut permasalahan penyalahgunaan narkoba merupakan permasalahan yang demikian komplek yang merupakan hasil interaksi 3 (tiga) faktor, yaitu sebagai berikut:

\section{Faktor individu}

a. Aspek Kepribadian

1) Tingkah laku anti sosial antara lain keinginan untuk melanggar, sifat memberontak, tak ingin hal yang besifat otoritas, menolak nilai-nilai tradisional, mudah kecewa, tidak sabar serta adanya keinginan diterima di kelompok pergaulan, dan untuk bergembira.

2) Kecemasan dan depresi antara lain tidak mampu menyelesaikan kesulitan hidup, menghindari rasa cemas, dan depresi, sehingga melarikan diri ke penyalahgunaan Narkoba.

b. Aspek Pengetahuan

1) Sikap dan kepercayaan antara lain mengikuti orang lain, tidak mengetahui bahaya Narkoba, ingin coba-coba agar diterima di lingkungan pergaulan. 
2) Keterampilan berkomunikasi menolak tekanan teman sebaya.

2. Faktor Lingkungan/Sosial

Faktor lingkungan/sosal antara lain kondisi keluarga/orang tua, pengaruh / kelompok sebaya, faktor sekolah, pengaruh iklan, dan kehidupan masyarakat modern.

\section{Faktor Ketersediaan}

Faktor ketersediaan antara lain : tersedia dimana-mana dan mudah diperoleh karena maraknya peredaran Narkoba, Indonesia sudah sebagai produsen Narkoba, bisnis Narkoba yang menjanjikan keuntungan besar, kultivasi gelap ganja di beberapa daerah di Indonesia serta penegakan hukum yang belum tegas dan konsisten (Hasril, 2013).

Dampak Penyalahgunaan Narkoba

Dampak penyalahgunaan narkoba pada seseorang sangat tergantung pada jenis narkoba yang dipakai, kepribadian pemakai dan situasi atau kondisi pemakai.Secara umum, dampak kecanduan narkoba dapat terlihat pada fisik, psikis maupun sosial seseorang (Haryanto, 2016).

\section{Dampak Terhadap Fisik}

a. Gangguan pada system syaraf (neurologis) seperti: kejang-kejang, halusinasi, gangguan kesadaran, kerusakan syaraf tepi.

b. Gangguan pada jantung dan pembuluh darah (kardiovaskuler) seperti: infeksi akut otot jantung, gangguan peredaran darah.

c. Gangguan pada kulit (dermatologis) seperti: penanahan (abses), alergi, eksim

d. Gangguan pada paru-paru (pulmoner) seperti: penekanan fungsi pernapasan, kesukaran bernafas, pengerasan jaringan paru-paru.

e. Sering sakit kepala, mual-mual dan muntah, murus-murus, suhu tubuh meningkat, pengecilan hati dan sulit tidur

f. Dampak penyalahgunaan narkoba terhadap kesehatan reproduksi adalah gangguan pada endokrin, seperti: penurunan fungsi hormon reproduksi (estrogen, progesteron, testosteron), serta gangguan fungsi seksual. 
g. Dampak penyalahgunaan narkoba terhadap kesehatan reproduksi pada remaja perempuan antara lain perubahan periode menstruasi, ketidakteraturan menstruasi, dan amenorhoe (tidak haid).

h. Bagi pengguna narkoba melalui jarum suntik, khususnya pemakaian jarum suntik secara bergantian, risikonya adalah tertular penyakit seperti hepatitis B, C, dan HIV yang hingga saat ini belum ada obatnya.

i. Penyalahgunaan narkoba bisa berakibat fatal ketika terjadi over dosis yaitu konsumsi narkoba melebihi kemampuan tubuh untuk menerimanya. Over dosis bisa menyebabkan kematian.

\section{Dampak Terhadap Psikis}

a. Lamban kerja, ceroboh kerja, sering tegang dan gelisah

b. Hilang kepercayaan diri, apatis, pengkhayal, penuh curiga

c. Agitatif, menjadi ganas dan tingkah laku yang brutal

d. Sulit berkonsentrasi, perasaan kesal dan tertekan

e. Cenderung menyakiti diri, perasaan tidak aman, bahkan bunuh diri

3. Dampak Terhadap Lingkungan

a. Akan mengganggu keharmonisan keluarga

b. Merongsong keluarga

c. Membuat aib keluarga

d. Hilangnya harapan keluarga

e. Mengganggu keamanan dan ketertiban

f. Mendorong tindak kejahatan

g. Mengakibatkan hilangnya kepercayaan

h. Menimbulkan beban ekonomi dan sosial yang besar

i. Dalam kehidupan sehari-hari di masyarakat termasuk juga dalam lingkungan sekolah, banyak dijumpai remaja yang hanya menjadi pemakai narkoba, pengedar ataupun kedua-duanya. Sebagai pengedar dan juga sebagai pemakai. Dalam lingkungan masyarakat yang lebih luas banyak dijumpai ulah para pengedar dan pemakai narkoba yang meresahkan. Mereka tidak segan-segan untuk melakukan tindak 
kriminal seperti menodong, mencopet, merampok, mencuri, marak hanya semata-mata untuk mendapatkan narkoba. Bagi mereka yang sudah sampai pada tingkat ketergantungan yang tinggi, Apapun resikonya tidak diperhitungkan lagi yang penting untuk mendapatkan narkoba (Falah Kharisma, 2016).

Berdasarkan uraian diatas, Kami merasa ingin ikut andil dalam upaya tersebut untuk membuat Pengabdian Kepada Masyarakat tentang Penyuluhan Bahaya Narkoba Terhadap Anak - Anak SD.

Adapaun pengertian narkoba menurut bahasa

\section{METODE}

Metode yang digunakan pada kegiatan Pengabdian Kepada Masyarakat yang berupa penyuluhan ini adalah dengan menggunakan metode ceramah, tanya jawab dan simulasi melalui media gambar dan pemutaran video tentang bahaya ketika menggunakan narkoba. Pemberian materi penyuluhan pertama tentang narkoba dan bahayanya ini disampaikan oleh Herudin, Lc,M.A. Lalu dilanjutkan oleh pemateri II Tarpan Suparman, S.Pd., M.Pd. Pemateri keIII Tia Latifatu Sa'diyyah. Materi dipaparkan dalam bentuk powerpoint dan video dengan menggunakan LCD. Akan tetapi sebelum pemateri melakukan tanya jawab dengan siswa siswi SDN Wanajaya II pemateri mengecek pengetahuan dasar yang dimiliki siswa tentang narkoba dan bahayanya, Setelah itu barulah pemateri memberikan kesempatan pada siswa siswi untuk bertanya. Pada sesi ini siswa terlihat sangat begitu antusias.

\section{HASIL PEMBAHASAN}

\section{Proses Pelaksanaan Kegiatan}

\section{a. Tahapan Persiapan}

1. Musyawarah terkait penyelenggaraan Pengabdian Pada Masyarakat dan pembentukan kepanitiaan.

2. Musyawarah penentuan waktu dan tempat kegiatan yang dilaksanakan oleh dosen yang akan mengadakan kegiatan. 
3. Setelah mendapat keputusan terkait tempat kegiatan yaitu di SDN Wanajaya II Teluk Jambe Barat selanjutnya dilaksanakan survey kelokasi tersebut untuk mengkonfirmasikan kesiapan SD tersebut untuk pelaksanaan P2M ini.

4. Musyawarah antar dosen terkait kesiapan tempat kegiatan dan penentuan jadwal kegiatan.

5. Konfirmasi kepemerintah desa tempat kegiatan terkait waktu penyeklenggaraan $\mathrm{P} 2 \mathrm{M}$.

6. Musyawarah fiksasi penyelenggaraan kegiatan P2M di SDn Wanajaya II dan sosialisasi mahasiswa yang akan diikutsertakan P2M.

\section{b. Tahapan Pelaksanaan}

1. Pelepasan oleh dekan FKIP sebelum pemberangkatan.

2. Pemberangkatan dari Kampus UBP Karawang jam 09.00 WIB.

3. Setelah kedatangan ditempat tujuan, selanjutnya dilaksanakan sosialisasi ke guru - guru SDN Wanajaya II terkait akan dilaksanaknnya P2M.

4. Kegiatan pelaksanaan Pengabdian Pada Masyarakt yang berupa Penyuluhan Bahaya Narkoba ini disampaikan di kelas 5 SDN Wanajaya II.

5. Setelah kegiatan penyuluhan selesai diadakan evaluasi terhadap kegiatan tersebut.

Tabel 1. Materi Kegiatan

\begin{tabular}{|l|l|c|}
\hline NO & \multicolumn{1}{|c|}{ Materi } & Pemateri \\
\hline \multirow{2}{*}{1} & $\begin{array}{l}\text { Definisi dan Undang } \\
\text { Undang Tentang Narkoba }\end{array}$ & Haerudin, Lc., M.A. \\
\cline { 2 - 2 } & Pengertian Narkoba & \\
\hline 2 & Jenis Jenis Narkoba & Tia Latifatu Sadiyyah,S.Pd. \\
& & M.Pd. \\
\hline
\end{tabular}




\begin{tabular}{|l|l|c|}
\hline \multirow{3}{*}{3} & $\begin{array}{l}\text { Faktor Faktor Penyebab } \\
\text { Penyalahgunaan Narkoba }\end{array}$ & \\
\cline { 2 - 2 } & $\begin{array}{l}\text { Dampak Penyalah gunaan } \\
\text { Narkoba }\end{array}$ & $\begin{array}{r}\text { Tarpan Suparman, S.Pd., } \\
\text { M.Pd. }\end{array}$ \\
\hline 4 & $\begin{array}{l}\text { Pemutaran Vidio } \\
\text { penyalahgunaan narkoba } \\
\text { dan akibatnya }\end{array}$ & Moderator \\
\hline 5 & Tanya Jawab & - \\
\hline
\end{tabular}

\section{Hasil Kegiatan}

Kegiatan Penyuluhan yang dikemas dalam kegiatan pengabdian kepada masyarakat UBP Karawang ini diawali dengan Sambutan dari Kepala sekolah SDN Wanajaya II. Kegiatan ini juga terlaksana dibantu dan bekerjasama dengan mahasiswa dan Mahasiswi PGSD . Kegiatan ini sangat di apresiasi dan di sambut positif oleh kepala sekolah SDN Wanajaya II beserta guru - guru - guru yang mengajar di SDN Wanajaya II Melalui sambutannya Kepala sekolah SDN Wanajaya II menyampaikan rasa terimakasih kepada UBP Karawang dan pemateri yang dengan suka rela membantu tugas KPA dan BNN dalam memberantas narkoba. Dalam pelaksanaan pemaparan materi Narkoba, jenis dan bahaya ditimbulkan disambut baik oleh siswa siswi SDN Wanajaya II. Mereka sangat antusias mengikuti tiap slide yang di tampilkan para pemateri, sesekali pertanyaan singkatpun muncul dari mereka. Kegiatan diakhiri dengan sesi Tanya jawab dan simulasi yang berupa pemutaran video singkat tentang jenis - jenis narkoba dan bahaya yang ditimbulkan akibat penggunaan narkoba. Dari data pengamatan dan Tanya jawab yang dilakukan meningkatnya pemahaman siswa tentang narkoba dari 5\% menjadi $90 \%$ 


\section{SIMPULAN}

Pengabdian Pada Masyarakat ini bertujuan untuk meningkatkan atau menguatkan pemahaman siswa siswi kelas 6 SDN Wanajaya II tentang narkoba,jenis dan dampak yang ditimbulkannya. Mengingat narkoba saat ini beredar dengan bebas dan dalam berbagai jenis dan bentuknya untuk memanipulasi para aparat yang terkait. Kegiatan penyuluhan ini dirasakan sangat penting dilakukan untuk membantu pemerintah dan menyelamtkan generasi genaresi muda harapan bangsa yang ditanamkan sejak dini agar mereka terhindar dari bahaya narkoba.

\section{DAFTAR PUSTAKA}

Mardani. H. (2008), Penyalahgunaan Narkoba Dalam Perspektif Hukum Islam Dan Hukum Pidana Nasional, Jakarta, PT. Raja Grafindo Persada.

Survei Nasional Badan Narkotika Nasional, (2011). Perkembangan Penyalahgunaan dan Peredaran Gelap Narkoba pada Kelompok Pelajar dan Mahasiswa di 16 Provinsi di Indonesia. Jakarta: Ringkasan Eksekutif BNN.

Prisaria, N. (2012). Hubungan Pengetahuan dan Lingkungan Sosial Terhadap Tindakan Pencegahan Penyalahgunaan NAPZA pada Siswa SMA Negeri 1 Jepara (Jurnal Sosial), diakses 10 Februari 2018; http://e-journal.undip.ac.id/.

Undang-Undang RI Nomor 35 Tahun, (2009), Tentang Narkotika.

Dedi humas, "Faktor Penyebab Penyalahgunaan Narkotika". Sumber: http://dedihumas. $\quad$ bnn.go.id/read/section/artikel/2013/07/23/704/faktorpenyebab-penyalahgunaan-narkotika(Diakses 27 Juli 2018)

Dimas Jaka, "Efek Dan Bahaya Narkoba". Sumber: http://dim4sjaka.blogspot.co.id/2008/ 09/efek-dan-bahayanarkoba09.html(Diakses 27 Juli 2018, jam 08.00 AM). 
Hasril, "Karya Tulis Ilmiah Tentang Narkoba" Sumber: https://hazrilmadridista.wordpress. com/2013/12/28/karya-tulis-ilmiah-tentangnarkoba/ (Diakses 09 November 2018, jam 10.00 AM).

Haryanto,"Dampak Penyalahgunaan Narkoba", http://belajarpsikologi.com/dampakpenyalahgunaan-narkoba / (Diakses 23 Juli 2018, Pukul 08.00 am).

Falah Kharisma, "Narkoba Pembunuh Karakter Bangsa" Sumber: http://falahkharisma. blogspot.co.id/2014/09/bahaya-penyalahgunaan-narkoba.html (Diakses 10 November 2018, jam 08.00 AM) 